\title{
Seismic Damage Model of High-Strength Reinforced Concrete Frame Columns
}

\author{
Guojun Zhang ${ }^{1, *}$ \\ ${ }^{1}$ College of Civil Engineering, Shanghai Normal University, Fengxian Shanghai 201418, China,zhgjxj@163.com
}

\begin{abstract}
In this paper, several existing seismic damage models as well as their characteristics were discussed first of all. And then it was figured out that variational history of incremental dissipated hysteretic energy of tentative frame columns under different loading cycle levels; the influence of axial compression ratio, type of stirrups, stirrup ratio, reinforcement ratio, strength grade of concrete and shear span ration on the incremental dissipated hysteretic energy was discussed and analysed. The damage index of tentative frame columns was compared and analysed according to the existing seismic damage models, and the seismic damage models adapt to high-strength concrete columns and ordinary-strength concrete columns were offered. The influence of shear span ration, axial compression ratio and stirrup ratio on the damage was discussed and analysed according to the variational history of the damage index under different loading cycle levels. Lastly through analysing all sorts of seismic damage models comparatively, the seismic damage model of high strength concrete frame columns is put forward, which offers good basement for further damage analysis.
\end{abstract}

\section{Seismic damage model}

The most intuitive manifestation of building structure under earthquake action is damage. It is not economical and realistic to expect the structure to have no damage or no damage under earthquake action. On the premise of allowing structural seismic damage, according to the historical seismic data, the seismic fortification level and importance of the structure, and on the basis of fully estimating the future seismic characteristics, it is a natural and reasonable pursuit for people to carry out seismic design of structures according to certain damage degree limits. Generally, the properties of seismic structures include elastic properties and inelastic properties ${ }^{[1]}$, and inelastic properties are also called damage properties. For the elastic properties, the elastic deformation reaction of the structure (such as the maximum elastic relative displacement between layers, the maximum elastic displacement of the vertex) is generally used to describe, which is caused by the seismic design codes of all countries in the world. For the evaluation of inelastic properties, the most widely used parameter is the maximum elastic-plastic displacement or displacement ductility coefficient of the structure (defined as the ratio of the maximum elastic-plastic displacement to the yield displacement of the structure). The investigation and experimental study of earthquake damage examples show that the structural earthquake failure forms are mainly divided into two categories :1) the first time to exceed the damage and 2) the cumulative damage. Because structural seismic damage is a broad term, the definition and calculation of damage are very complicated. choose what kind of parameters can reflect the change of structural mechanical properties to describe the damage degree of the structure, which is not only related to the concept and definition of damage, but also makes the selected parameters easy to calculate, can be measured directly or indirectly, and can describe the development of structural seismic damage, reflecting the of damage mechanism ${ }^{[2]}$.

From the point of view of the number of damage parameters, the seismic damage model of the structure can be divided into single parameter damage model and double parameter damage model.

(1) Single-parameter earthquake damage model

The single parameter seismic damage model holds that the seismic damage of a structure or component can be described by a single damage parameter $\Delta$, and the calculated value of the member is destroyed $\Delta_{c}$ it is greater than its limit allowable value $\Delta_{u}$. The damage index model described by a single damage parameter can generally be expressed as:

$$
D M=f\left(\Delta_{c}, \Delta_{u}\right)
$$

(2) Two-parameter earthquake damage model

Domestic and foreign scholars have put forward a lot of double-parameter seismic damage models, more mature and widely used or Park models. To consider the accumulation of hysteretic energy dissipation based on deformation analysis, in 1985, American scholars Park Y.J. Hong Watson (AngA.H.S.) and Wen Yigui (WenY.K.) first

"Corresponding author: zhgjxj@163.com 
proposed a linear combination of maximum deformation and cumulative hysteretic energy dissipation ${ }^{[3]}$. They defined the damage index $D M$ as:

$$
D M=\frac{X_{m}}{X_{u}}+\beta \frac{E_{h}}{F_{y} X_{u}}
$$

The $X_{u}$ is the ultimate deformation of the member under the action of single withering load, the $F_{y}$ is the yield shear force of the member, the $X_{m}$ and $E_{h}$ are the maximum elastic-plastic deformation and cumulative hysteretic energy consumption of the member under the action of earthquake; and $\beta$ is the energy dissipation factor of the member. For shear structure, the following formula is calculated:

$$
\beta=\left(\begin{array}{l}
-0.447+0.073 \lambda \\
+0.24 \lambda_{\mathrm{N}}+0.314 \rho_{s}
\end{array}\right) \times 0.7^{100 \rho_{w}}
$$

The $\lambda$ is the shear span ratio of the member, the $\rho_{s}$ is the reinforcement ratio of the longitudinal reinforcement, and the $\rho_{w}$ is the volume hoop ratio.

For curved structures $\beta$ can be calculated by following formula:

$$
\beta=\left[\begin{array}{l}
0.37 \lambda_{N}+ \\
0.36\left(k_{\rho}-0.2\right)^{2}
\end{array}\right] 0.9^{100 \rho_{W}}
$$

Formula $k_{\rho}$ normalized reinforcement ratio, $k_{\rho}=\frac{\rho_{t} f_{y}}{0.85 f_{c}^{\prime}}$.

\section{Damage to frame columns}

\subsection{Comparison of cumulative damage of frame columns}

\subsubsection{Comparison of cumulative hysteretic energy consumption}

Cumulative hysteretic energy consumption of the specimen is of the area surrounded by the hysteretic curve ${ }^{[4]}$, calculated from the following formula:

$$
E=\int F d x
$$

Materials [6] according to the characteristics and practical engineering experience of the frame column in the frame arrangement system of the main workshop, 9 high strength concrete frame columns and 7 general concrete cantilever test frame columns are tested repeatedly at low cycle. The concrete strength grades are C60 and C30, respectively different shear span ratio, axial compression ratio, stirrups form and hoop ratio are adopted. According to these test results, the damage model of frame column is analysed and studied.
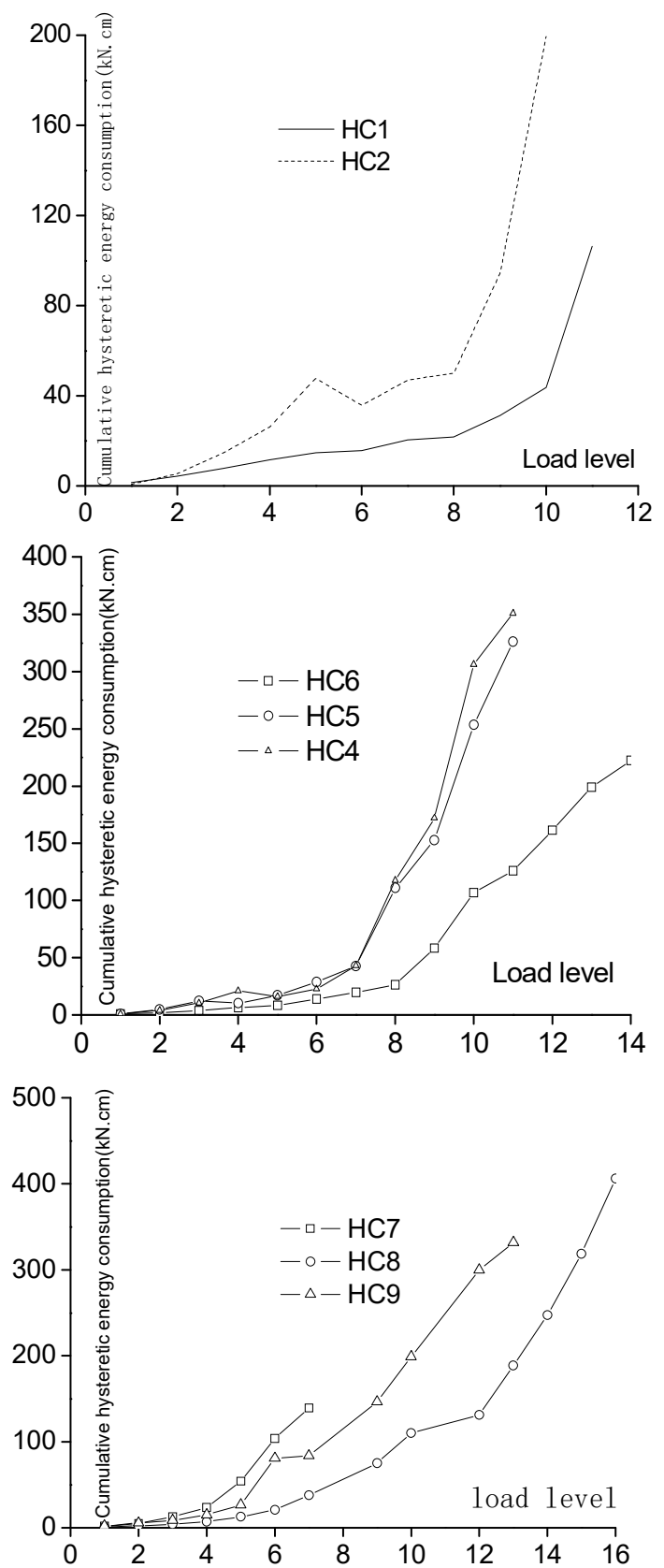

Fig.1.Variation of Accumulated Hysteresis Energy Consumption with Loading Level of High Strength Concrete Frame Column

Figures 1 and 2 show the variation of cumulative hysteretic energy consumption with the loading cycle level. The loading cycle level of the transverse coordinates in the diagram corresponds to the single cycle before yielding, and the yield is corresponding to the two to three weeks cycle of each amplitude. 

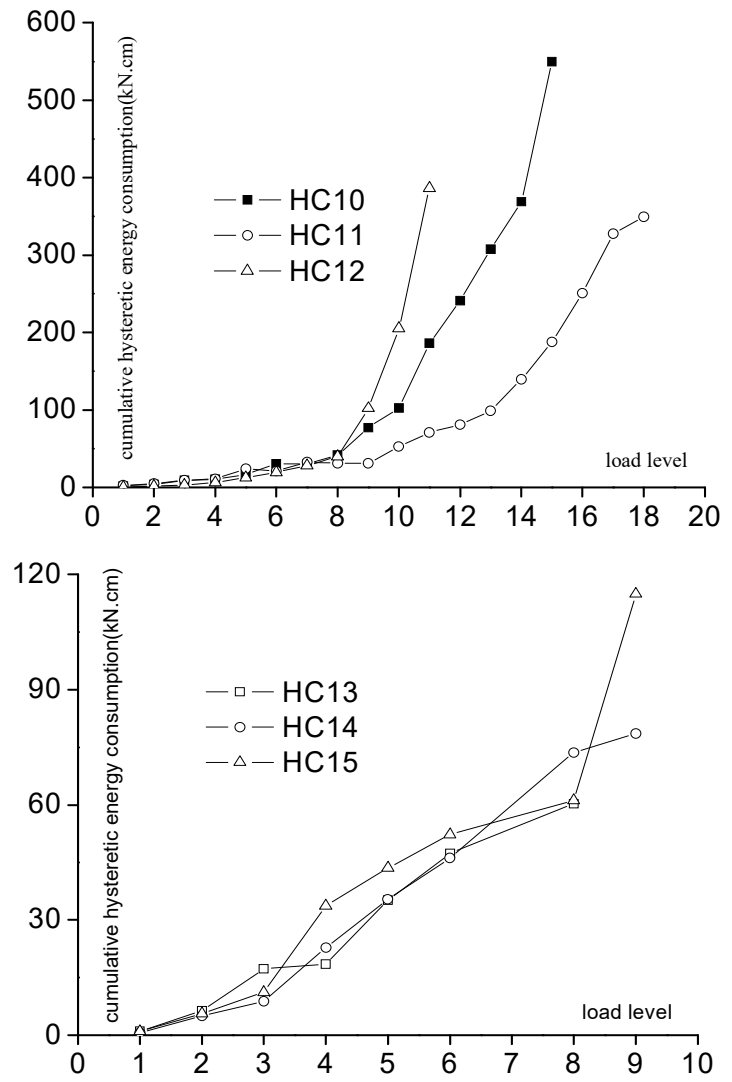

Fig .2. Variation of cumulative hysteretic energy dissipation with loading level of ordinary concrete frame columns

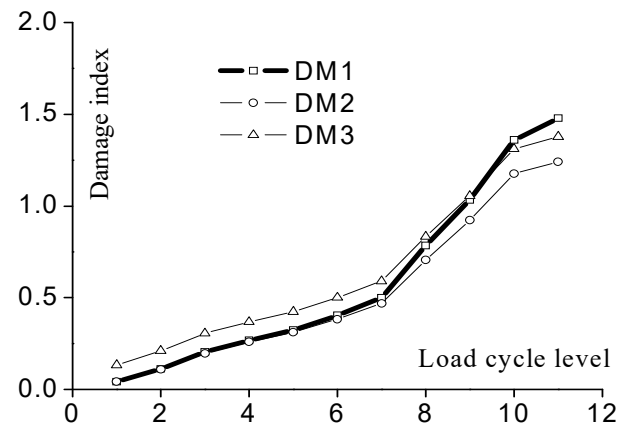

Damage Model of High Strength Concrete Frame Column

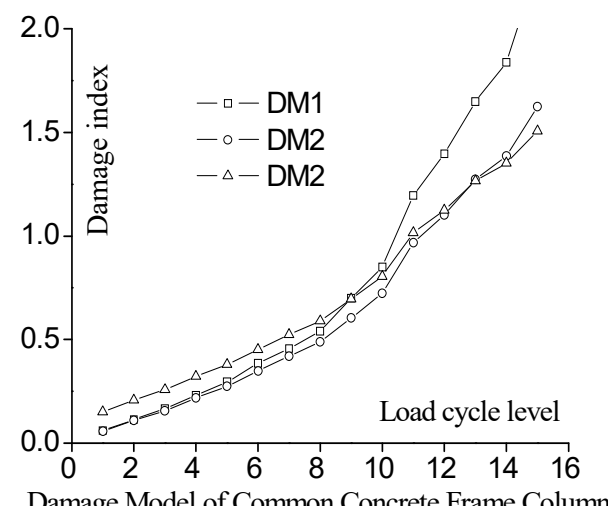

Fig. 3. Comparison of three damage indices

We can see from Figures 1 and 2 that with the increase of axial compression ratio, the cumulative hysteretic energy consumption becomes smaller and smaller. The HC4, HC5 and HC6 of high strength concrete members and the $\mathrm{HC} 10, \mathrm{HC} 11$ and $\mathrm{HC} 12$ of ordinary concrete members have the same conclusion. However, high strength concrete members have less hysteretic energy consumption than ordinary concrete.

Under the same axial compression ratio, the cumulative hysteretic energy consumption is related to the form of stirrups, hoop ratio, longitudinal reinforcement ratio, concrete strength and shear span ratio. Hysteretic energy consumption of rectangular hoop, cross-pull hoop and well-shaped hoop members increases in turn, and increases with the increase of hoop ratio and reinforcement ratio ${ }^{[6]}$.

\subsubsection{Selection of earthquake damage model}

For high strength concrete frame columns, damage index calculated by formula (2) and $\beta$ value calculated by formula (3) are in good agreement with experimental phenomena; For ordinary concrete frame columns, damage index calculated by formula (2) are in good agreement with experimental phenomena. The damage index calculated by formula (5) is too large, if $0.1 \%$ after a week of loading. The concept of damage is quite different. In figure 3, damage index $\beta$ is calculated by formula (2); damage index $D M 2$ is calculated by formula (2) and formula (3).

\subsubsection{Comparison of damage indices}

The damage model of formula (2) is used in figure 4. For ordinary concrete frame column. It can be seen from figure 4 that the damage of frame column is mainly affected by shear span ratio, axial compression ratio, stirrups form and hoop ratio ${ }^{[4-5]}$.

(1) As the shear-span ratio increases, energy dissipation factor $\beta$ also increased accordingly. Such as high strength concrete specimen $\mathrm{HC} 1$ and $\mathrm{HC} 2$ are smaller than other specimens, the $\mathrm{HC} 10, \mathrm{HC} 11$ and $\mathrm{HC} 12$ of ordinary concrete specimens are smaller than that of $\mathrm{HC} 13$, HC14 and HC15.

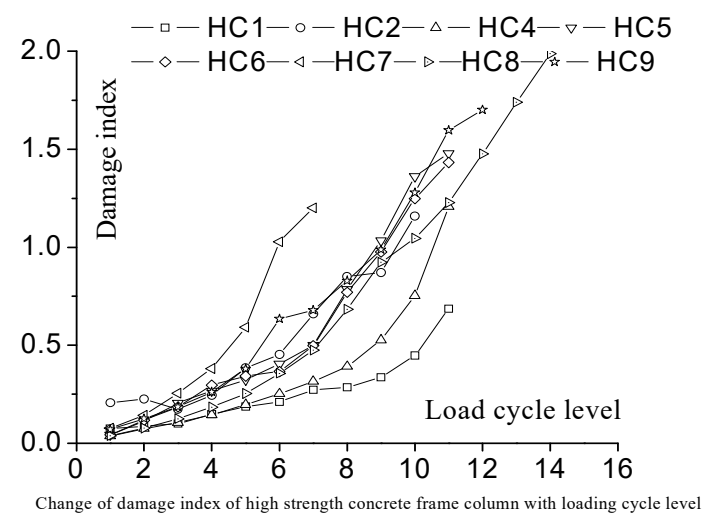




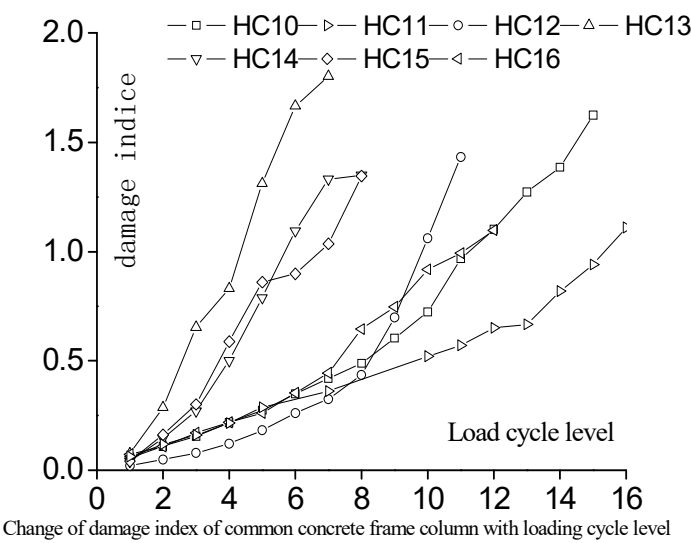

Fig. 4. Damage index with loading level

(2) As the axial compression ratio increases, the damage also increased accordingly. Such as high strength concrete specimen $\mathrm{HC} 4, \mathrm{HC} 5$ and $\mathrm{HC} 6$ and ordinary concrete specimen $\mathrm{HC} 10, \mathrm{HC} 11$ and $\mathrm{HC} 12$ damage increased in turn.

(3) As the hoop ratio decreases, the damage of the specimen increases; the damage of well type hoop, cross tension hoop and rectangular hoop increases in turn. Such as high strength concrete specimen $\mathrm{HC} 9, \mathrm{HC} 8$ and $\mathrm{HC} 7$ and ordinary concrete specimen $\mathrm{HC} 15, \mathrm{HC} 14$ and $\mathrm{HC} 13$, the damage value increases in turn.

\subsection{Damage Model of High Strength Concrete Frame Column}

From the above test results, the damage model of formula (2) can be adopted for both high strength concrete frame columns and ordinary concrete frame columns. Through the study of the damage of high strength concrete frame column, it is found that the energy dissipation factor $\beta$ calculated by formula (5) is slightly larger, and the energy dissipation factor $\beta$ is obtained:

$$
\beta=0.66^{\rho_{w}}\left(-0.266+0.18 \rho_{s}+0.06 \lambda+0.45 \frac{N}{f_{c 0} A_{c}}\right)
$$

Type: $\rho_{W}-$ transverse hoop ratio, $\rho_{s}-$ longitudinal reinforcement ratio, $\lambda-$ shear span ratio, $\frac{N}{f_{c 0} A_{c}}$ - axial compression ratio.

The $\beta$ value of energy dissipation factor calculated by formula (6) is related to transverse hoop ratio $\left(\rho_{W}\right)$ 、 longitudinal reinforcement ratio $\left(\rho_{S}\right)$, shear span ratio $(\lambda)$ and axial compression ratio $\left(N / f_{c 0} A_{c}\right)$, but not to concrete compressive strength $f_{c 0}$. It can correctly reflect the damage performance of high strength concrete frame column.

\section{Conclusions}

Based on the calculated cumulative hysteretic energy consumption of high strength concrete test frame columns with the change of loading cycle level, it can be found that with the decrease of axial compression ratio and the increase of hoop ratio and reinforcement ratio, the cumulative hysteretic energy consumption increases accordingly. Under the same axial compression ratio, the cumulative hysteretic energy consumption is related to the form of stirrups, hoop ratio, longitudinal reinforcement ratio, concrete strength and shear span ratio. The hysteresis energy consumption of rectangular hoop, crosspull hoop and well-shaped hoop members increases in turn, and the hysteresis energy consumption increases with the increase of hoop ratio and reinforcement ratio. The main damage of frame column is shear span ratio, axial compression ratio, stirrups form and hoop ratio. As the shear-span ratio increases, the energy dissipation factor $\beta$ increases accordingly; with the increase of axial compression ratio, the damage increases accordingly; with the decrease of hoop ratio, the damage of specimen increases; the damage of well hoop, cross hoop and rectangular hoop increases in turn. Finally, through the comparison and analysis of each earthquake damage model, the earthquake damage model of high strength concrete frame column is put forward.

\section{References}

1. B.Q. Liu. Failure Criteria and Reliability Analysis of Seismic Structures. Beijing: China Building Materials Industry Press (1996).

2. G.J. Zhang, B.Q. Liu, Y.B. Li, T. Wu. Advances in the Study of Damage Criteria for Seismic Structures. Architectural Science Research, Sichuan, No.3:68 71(2002).

3. Park Y. J. and Ang A. H-S, A Mechanistic Seismic Damage Model for Reinforced Concrete, J. Structure Engineering, ASCE, 111(4): 740 756(1985).

4. G C Beolchini, D Galeota, M M Giammatteo and M Zulli. Seismic Behavior of high Strength RC Columns. 12th World Conference on Earthquake Engineering. Auckland, New Zealand: 2000 New Zealand Society for Earthquake Engineering, 0593: $1 \sim 8(2000)$.

5. H.Q. Li, L.H. Lei, X.L. Lu. Study on Resistance to Low-cycle Fatigue Damage of Reinforced Concrete Bending Members, Journal of Nanjing Institute of Architectural Engineering, No. 3:10 16(1998).

6. G.J. Zhang. A Study on Seismic Performance of High-strength Concrete Frame Columns in Largescale Thermal Power Plant. Doctoral thesis of Xi'an University of Architectural Science and Technology: Xi'an University of Architectural Science and Technology (2003). 